\title{
Macrophyte meadows mediate the response of the sediment microbial community to ultraviolet radiation
}

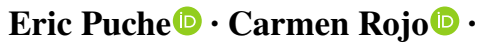 \\ Matilde Segura $\odot$ María A. Rodrigo $(\mathbb{D}$
}

Received: 14 December 2020 / Revised: 5 July 2021 / Accepted: 7 July 2021 / Published online: 20 July 2021

(C) The Author(s) 2021, corrected publication 2022

\begin{abstract}
The decrease of the water level in Mediterranean wetlands due to global warming allows UVR to reach the sediment microbial community. Macrophyte meadows, through their structure and compounds contribution, exert influence on this community. Our goal was to establish how the sediment microbial community of a wetland is harmed by UVR, and how the macrophytes mitigate such effects. We performed a field factorial experiment (UVR and macrophytes as factors) in a Mediterranean wetland. The abundance and composition of the sediment microbial community (bacteria, Archaea, microalgae and cyanobacteria) and sediment stoichiometry in superficial and sub-superficial layers were analysed. The microbial community was altered even by the small doses of UVR of the Mediterranean coastal wetlands by decreasing the periphyton abundance, including bacteria involved in $\mathrm{C}$ and $\mathrm{N}$ metabolism. Submerged macrophytes favoured the periphytic biofilm and increased sub-superficial carbon and
\end{abstract}

Handling editor: Stefano Amalfitano

Supplementary Information The online version contains supplementary material available at https://doi. org/10.1007/s10750-021-04662-2.

E. Puche $(\bowtie) \cdot$ C. Rojo $\cdot$ M. Segura $\cdot$ M. A. Rodrigo Cavanilles Institute of Biodiversity and Evolutionary Biology, University of Valencia, c/ Catedrático José Beltrán 2, Paterna, 46980 Valencia, Spain e-mail: eric.puche@uv.es nitrogen amounts, by promoting bacteria involved in their cycles. The shade exerted by the meadows minimized the UVR effects, driving to a community similar to that of the UVR-filtered environment. Therefore, macrophytes, through different mechanisms, can mitigate the harmful effects of UVR in sediment communities. Thus, the conservation of macrophyte meadows in highly vulnerable wetlands becomes crucial in a global change context.

Keywords Stoichiometry · Charophytes · Denitrifying bacteria $\cdot$ Mediterranean wetland . Periphyton biofilm · UVR

\section{Introduction}

Within the aquatic microbial community organisms tightly linked to the sediment of waterbodies, or the sediment microbial community, are of special interest (Orland et al., 2020). This is a complex assemblage occupying different layers of sediment with distinct physical and chemical conditions (Spring et al., 2000). Differences in the abundance, composition, and functions of this community are expected in the different layers (Baveye et al., 2019). In the superficial sediment, where photosynthetic active radiation arrives, there is the periphyton biofilm composed of a variety of autotrophic and heterotrophic microorganisms, mostly benthic microalgae and cyanobacteria, but also bacteria and Archaea (Rysgaard et al., 1995; 
Song et al., 2016). This assemblage plays significant roles in the primary productivity, energy flow, and nutrient cycling in aquatic ecosystems (Azim et al., 2005; Canfield et al., 2010), and it is used to sort out water quality (Sabater et al., 2007; Wu et al., 2018). In addition, the complex bacterial assemblage of the sediment microbial community also develops relevant biogeochemical activity in the sub-superficial anoxic sediment (Morina et al., 2018).

It is well-known that microbial community components are vulnerable to both biotic and abiotic environmental conditions on a local scale; for example, being affected by light quality, temperature, nitrogen pollution (Navarro et al., 2009; Baron et al., 2013), or the presence of macrophytes (Rojo et al., 2017a; Xian et al., 2020). Therefore, it is predictable that this community will change in abundance and composition in the different sediment layers when certain stressors act. Furthermore, these shifts in the sediment microbial community are especially worrying in shallow lakes or wetlands, since these ecosystems are highly vulnerable to global change (Jeppesen et al., 2014). In fact, disturbances can occur rapidly in these systems (within a few days), making shallow lakes a type of temporary waterbody, where the microbial community will have to respond in the short-term (Rojo et al., 2017b).

The most studied foreseeable environmental changes in lakes are warming, eutrophication, salinization, and changes in light quality (Jeppesen et al., 2014; Carrillo et al., 2015; Rojo et al., 2019). In this regard, Mediterranean shallow lakes or wetlands represent a paradigmatic case because they are already suffering the concomitant effects of these mentioned factors (Giorgi \& Lionello, 2008; Parcerisas et al., 2012; IPCC, 2014; Cabrerizo et al., 2020). Moreover, these processes occur in ecosystems sited in areas with abusive anthropogenic nitrogen inputs (i.e. coastal Mediterranean area where there is intensive agricultural fertilization; Jeppesen et al., 2011). Therefore, the biotic communities involved in the $\mathrm{N}$ biogeochemical cycle, particularly those involved in denitrifying processes in the sediments, are of main interest (Canfield et al., 2010; Jordan et al., 2011).

Concerning the alteration in light quality, one of the consequences of the loss of water column depth in aquatic ecosystems will be that ultraviolet radiation (UVR hereafter) can reach the bottom of these systems, impacting the benthic community by affecting a wide range of aquatic organisms, including microorganisms from the sediment microbial community (Rojo et al., 2019). The harmful effect of UVR on the photosynthetic metabolism and DNA of aquatic primary producers, such as microalgae and cyanobacteria, reduces their production (Barrado-Moreno et al., 2017). Moreover, UVR triggers a loss in their diversity towards more resistant taxa (Harrison \& Smith, 2009; Rojo et al., 2012). Furthermore, UVR could also directly modify the abundance and composition of the aquatic bacterial community (Manrique et al., 2012; Xiao et al., 2020), and indirectly affect it by altering its matter and energy sources (Mayer et al., 2006).

With respect to the submerged macrophytes, such as charophytes, these green macroalgae, through their contribution of organic matter rich in nitrogen compounds, could be accompanied by a greater density and activity of denitrifying bacteria (Rodrigo et al., 2007, 2013; Morina et al., 2018; Rojo et al., 2020). Consequently, this will have implications in the sediment stoichiometric composition (Hansson et al., 2005; Zhang et al., 2013), being beneficial to the ecosystem (Rabalais, 2002) since this activity would reduce the internal nitrogen loading of the system. The presence of macrophytes affects denitrification rates by altering the oxygen conditions (Veraart et al., 2011) and organic carbon availability (Vermeer et al., 2003; Rodrigo et al., 2007), both in the water column and in the sediment. In addition, macrophyte morphological architecture both above and below ground (e.g. the rhizoidal system) provides a landscape to develop the microbial community, and could imply beneficial shading for the sediment community, minimizing the harmful UVR effect in shallow waterbodies (Hilt \& Gross, 2008; Morina et al., 2018; Dai et al., 2019; Puche et al., 2020). Therefore, it is expected that aquatic plant meadows affect not only the physical and chemical properties of the sediment (Neubauer et al., 2005), but also the structure and function of the microbial communities in the periphyton biofilm and sub-superficial layers (Morina et al., 2018).

Hence, our main goal is to establish how UVR, and the presence of macrophyte meadows, affect the structure-function of the sediment microbial community (both the periphytic microbial community and that of sub-superficial sediment layers) from a nitrateenriched system. We disentangle different effects 
of these two factors and test our hypothesis that the presence of macrophyte meadows, through different mechanisms, mitigates the harmful effect, of UVR.

\section{Methods}

Experimental design

\section{Obtaining the charophytes and the preparation of cultures}

The charophyte species chosen for the study was Chara hispida Linnaeus (Characeae family), a freshwater benthic macroalga which is anchored to the substrate by means of rhizoids. This is a cosmopolitan species, naturally present in freshwater ecosystems in the Mediterranean region and it has previously been used in studies related to global change (Rojo et al., 2017a). The original plant material was collected from a small Mediterranean coastal lagoon $\left(39^{\circ} 12^{\prime}\right.$ $29^{\prime \prime} \mathrm{N}$ and $0^{\circ} 14^{\prime} 5^{\prime \prime} \mathrm{W}$; reference system WGS84) close to where the experiment took place. Using this collected material, small plants of C. hispida were cultivated in an indoor culture room and, when the roots had sprouted, they were planted in the limnocorrals (more detailed in Supplementary Material).

\section{Two-way ANOVA experimental design}

The experiment followed a two-way ANOVA design: (i) the presence or absence of charophytes $(\mathrm{CH}$ or $\mathrm{NCH}$, respectively), and (ii) sunlight or sunlight with reduced UVR (hereinafter termed PAB and PAR, respectively). Therefore, the experiment had four conditions (CHPAB, CHPAR, NCHPAB, NCHPAR) with three replicates of each of them, which meant a total of 12 limnocorrals were needed. The 12 limnocorrals were located in a protected wetland, El Tancat de la Pipa $\left(39^{\circ} 21^{\prime} 51^{\prime \prime} \mathrm{N}\right.$ and $0^{\circ} 20^{\prime} 47^{\prime \prime} \mathrm{W}$; reference system WGS84), a restored area from former rice fields belonging to the Albufera de València Natural Park (Fig. S1a). The limnocorrals were quadrangular cages anchored to the sediment; the sides and tops were covered with plastic mesh and plastic sheets, respectively, to prevent animal incursions (Rodrigo et al., 2013; Fig. S1b, c). For the PAB treatment, the limnocorrals were covered with polyethylene sheets which transmitted $90 \%$ of photosynthetic active radiation (400-700 $\mathrm{nm})$ and the majority of UVR [100\% UVB (280-320 nm) and 92\% UVA (320-400) $\mathrm{nm})]$.

The UVR filter sheet for the PAR treatment transmitted $80 \%$ of the photosynthetic active radiation, $48 \%$ of the UVB and $56 \%$ of the UVA. The underwater radiation doses were measured in each limnocorral with a JAZ system spectrometer (Ocean Optics, Inc.; details in Supplementary Material). The significant difference in the UVR doses in the limnocorrals of these treatments was tested (Table S1). The limnocorrals were placed at a distance of $1 \mathrm{~m}$ from each other, occupying a total area of approximately $25 \mathrm{~m}^{2}$; the treatments corresponding to each limnocorral were established randomly (Fig. S1d). For the $\mathrm{CH}$ treatment, 16 small pots $(4.6 \mathrm{~cm}$ diameter) with charophytes belonging to the laboratory stock were planted in each limnocorral (Fig. S1e), thus, 96 cultures in total. These pots were transplanted, keeping the small portion of the substrate (a mixture in proportion 1:1 of previously autoclaved sediment and commercial sand) which held the rhizoids to ensure their anchorage in the new site. Hence, approximately $10 \%$ of the sediment surface of these limnocorrals was substituted by introduced substrate, and the charophyte surface coverage after planting was $30 \%$. In the NCH-treatment limnocorrals 16 sediment units (from pots containing the same mixture of substrate as for charophyte cultures, treated in the lab the same as the former ones) were also placed in each limnocorral to simulate the same disturbance on the natural sediment. The experiment lasted seven weeks, after an acclimatization period of some weeks to make sure the plants were growing. At the beginning of the experiment (after the acclimatization period) 3 cores were extracted per limnocorral, and at the end of the experiment 5 cores were extracted per limnocorral in order to include the possible spatial heterogeneity due to the treatments. In each core, two parts of the substrate were distinguishable according to their coloration and the presence of primary producers (Fig. S1f): a lighter surface part corresponding to the more oxygenated zone where the periphytic biofilm was located (hereafter the superficial layer), and a deeper part, darker in colour, corresponding to the more anoxic part (hereafter the sub-superficial layer). In the field, these layers were separated and kept in sterile plastic pots. Once in the laboratory, the superficial parts of the cores of each limnocorral were 
homogenized; the same procedure was carried out with the cores from the sub-superficial layers. These integrated sediment samples were the material used to obtain the data used in this study.

\section{Limnological conditions: water column, sediment and charophytes}

Limnological conditions, including physical, chemical and stoichiometric variables in the water column and in the sediment were reported for each limnocorral at the beginning and end of the experiment (Tables $\mathrm{S} 1, \mathrm{~S} 2$ ).

From the extracted sediment cores in each limnocorral, and the subsequent homogenization of the superficial and sub-superficial layers (explained above), subsamples of sediment were destined for the analysis of the chemistry of the sediment interstitial water and the sediment stoichiometry. The subsamples for the interstitial water analysis were centrifuged at $500 \times \mathrm{g}$ for $15 \mathrm{~min}$ (centrifuge Sorvall ST 16R) and the supernatant (interstitial water) was analysed for main chemical variables (following APHA, 2005 techniques) and stoichiometry. The carbon and nitrogen contents of these samples were measured using a Perkin-Elmer CHSN-2400 elemental analyser. The phosphorus concentration was measured following the technique described in Sparks et al. (1996) which solubilizes all phosphorus fractions, and this was later measured as Soluble Reactive Phosphorus in a Seal-3 QuAAtro AQ2 auto-analyser. The precision (reproducibility) of all measurements was $0.22 \%, 0.06 \%$ and $0.006 \%$ for carbon, nitrogen and phosphorus, respectively. The limits of detection were $0.10 \%, 0.05 \%$ and $0.008 \%$ for carbon, nitrogen and phosphorus, respectively. The subsamples for sediment stoichiometric analyses were kept in tubes in the freezer at $-20^{\circ} \mathrm{C}$ until proceeding with the stoichiometric analyses (following the same procedures explained above).

The charophyte meadows were collected at the end of the experiment (by cutting the parts above the sediment) and their biomass (fresh weight) was measured. Furthermore, samples of charophytes from the different conditions were analysed for photosynthetic pigments and for UVR absorbing compounds concentration (for detailed methodology see Rubio et al., 2015). There were no differences in plants or meadows based on the radiation treatments (Table S3).
Response variables

The response variables were selected due to their common and effective use to assess changes in the sediment microbial community: bacterial density (Duhamel \& Jacquet, 2006) and their OTUs diversity (Dai et al., 2019; Menéndez-Serra et al., 2019), microalgae and cyanobacteria biomass and their specific diversity (Rojo et al., 2017a; Morina et al., 2018), as well as the changes in taxonomicfunctional relevant groups, both in bacteria and in microalgae and cyanobacteria (Gugliandolo et al., 2016).

\section{Bacteria: counting and density estimation}

The preparation of the samples $(0.5 \mathrm{ml}$ of fresh sediment) for counting by flow cytometry was carried out from an adaptation of the dilution/fixation/staining protocol to analyse freshwater bacteria in lake sediments proposed by Duhamel \& Jacquet (2006) (see Supplementary Material for more details). Once each sample was prepared, it was put into the cytometer (Cytomics FC 500 Beckman Coulter) and a high flow rate for $120 \mathrm{~s}$ was programmed; this process was repeated 3 times per sample in three different sessions. These results were analysed with the specific program Flowing Software 2. A dot plot was made with channels FL1 and FL4, which discriminate bacteria from other particles since bacteria stained with SYBR Green II have a maximum emission collected by channel FL1, and a minimum collected by FL4. From this graph, the region corresponding to the bacteria was delimited (more details in Fig. S2).

In parallel, the water content of the sediment (both for superficial and sub-superficial layers) was assessed by weighing aliquots (known volume) of this sediment fresh weight (FW) initially and dry weight (DW) after $24 \mathrm{~h}$ at $70^{\circ} \mathrm{C}$. The relationship between the FW and DW of the sediment was calculated by measuring them from aliquots of all the samples $\left(\mathrm{DW}=0.179 \times \mathrm{FW} ; R^{2}=0.99\right)$. Thus, bacterial counting was normalized by the grams of DW of sediment considered for the sample, and, in this way, the number of bacteria per gram of DW of sediment for each layer and each limnocorral was obtained. 


\section{Bacteria and Archaea: composition}

For DNA analyses, $0.25 \mathrm{~g}$ of sediment was used following the PowerSoil ${ }^{\circledR}$ DNA Isolation Kit (Qiagen) manufacturer's protocol. 16S rRNA gene sequencing and bioinformatic data analyses were carried out at the Genomics core facility of the SCSIE-Universitat de València. Variable V3 and V4 regions of the 16S rDNA were amplified following the $16 \mathrm{~S}$ rRNA gene Metagenomic Sequencing Library Preparation Illumina protocol (Cod. 15044223 Rev. A). Gene-specific primers (PCR1_f: 5'-TCGTCGGCAGCGTCA GATGTGTATAAGAGACAGCCTACGGGNGGC WGCAG-3'; PCR1_r: 5'-GTCTCGTGGGCTCGG AGATGTGTATAAGAGACAGGACTACHVGGG TATCTAATCC-3') containing Illumina adapter overhang nucleotide sequences were selected according to Klindworth et al. (2013). After 16S rDNA gene amplification for each sample, the multiplexing step was performed using the Nextera XT Index Kit. Amplicon libraries were sequenced using a $2 \times 300$ $\mathrm{pb}$ paired-end run on a MiSeq Sequencer according to the manufacturer's instructions (Illumina). Sequencing data were demultiplexed using the Illumina bcl2fastq $\odot$ program. Forward and reverse raw reads were checked for quality, adapter trimmed and filtered using AfterQC (Chen et al., 2017) and FastQC v0.11.8 (http://www.bioinformatics.babraham.ac.uk) tools.

Sequence analysis was conducted using the 16S-based metagenomics workflow of MiSeq Reporter v2.5 (Illumina), including forward and reverse read joining, data filtering and taxonomic annotation. OTUs clustering and classification at several taxonomic levels were performed using a highperformance implementation of the Ribosome Database Project (RDP) Classifier algorithm, described in Wang et al. (2007). Taxonomic classification was carried out using an Illumina-curated version of the Greengenes database (http://greengenes.secondgeno me.com/downloads/database/13.5).

The results were reported as the number of sequences (hits) obtained on the different sample sizes analysed and the percentage of sequences from each OTU. To obtain a measure of the abundance of each OTU these percentages were used on total bacteria abundance (cells/g DW sediment), obtaining an approximation to hits of each OUT/g DW of sediment; this is an abundance measurement which is more easily comparable to the abundance of other organisms inhabiting the sediment, such as microalgae and cyanobacteria. For each sample, we selected OTUs with more than 300 hits, or $0.1 \%$ of total hits; although some OTUs are at the species level, we considered the matrix of the genera more trustworthy (Fox et al., 1992; Azua-Bustos et al., 2018). For the comparative analysis of sample composition, we used phyla that had more than $1 \%$ of hits. Archaea sequences, despite being detected in all the samples, did not result in more than $1 \%$ of hits of each sample.

\section{Abundance and composition of microalgae and cyanobacteria}

To study the microalgae and cyanobacteria assemblages, a subsample of the sediment from the superficial layer of each core was weighed. Then, this fraction was washed by stirring it in $50 \mathrm{ml}$ of deionized water. This water preserved with a Lugol's iodine solution was the sample used to observe and count the organisms.

Taxonomic classification (at the finest possible resolution), counts and measurements of these populations were conducted using Utermöhl chambers under an inverted microscope at $\times 400$ and $\times 1000$ magnification following standard protocols (cited in Rojo et al., 2012). To determine whether most of the periphytic species richness of each assemblage was covered, a species accumulation curve was plotted as a saturating criterion (Rojo et al., 2017a). Counted individuals were single cells, colonies and filaments; their biovolume was calculated following Hillebrand et al. (1999). Therefore, the biomass for each species and site was expressed as $\mathrm{mm}^{3} / \mathrm{g}$ DW of sediment.

\section{Diversity analysis}

We also calculated the diversity for each assemblage in the sediment as the richness, the effective number of species and the evenness value. We used the Shannon-Wiener index ( $H$, using natural logarithms), which is sensitive to less frequent species (Shannon \& Weaver, 1949), and determined the departure from the maximal value of this index with the evenness value (expH/richness). The effective number of species was calculated following Jost et al. (2010) as $\operatorname{expH}$. These diversity indicators were calculated on both the biomass $\left(\mathrm{mm}^{3} / \mathrm{g}\right.$ DW of sediment) of 
microalgae and cyanobacteria species and the density of hits (hits/g DW sediment) of bacterial phyla.

\section{Response variables at the beginning and end of the experiment}

All the above-mentioned response variables were obtained at the beginning of the experiment to test that their values were not significantly different between treatments $(P>0.05$; Table S4). Once proved that the conditions at the beginning of the experiment, after the considerable disturbance of the setup, did not show significant differences among treatments, we assessed, at the end of the experiment, the effects of the tested factors acting on the sediment microbial community over 7 weeks.

\section{Statistical analyses}

The normality of the residuals and the homoscedasticity of the variances of data were verified using the Shapiro-Wilk and Levene tests, respectively. When both conditions were met, two-way ANOVAs were performed to study the effect of the tested factors (charophytes and radiation), as well as their interaction on the response variables. When the requirements for ANOVA were not met, non-parametric tests were used (i.e. Mann-Whitney test) and then Mann-Whitney $U$ and Kruskal-Wallis $\left(\chi^{2}\right)$ tests were used for comparisons between two, or more than two groups. When considered helpful, correlations (Pearson coefficient) between variables were carried out.

SIMPER analyses, based on Euclidean distances and considering the set of comparisons between conditions, were performed for superficial and subsuperficial samples to highlight which phyla of bacteria are the most relevant for characterizing the conditions. Principal component analyses were performed to order the samples based on the selected main bacterial phyla by SIMPER. To order samples based on their sediment microbial composition, a cluster analysis (Euclidean distances and UPGMA) was performed. Statistically significant differences were considered from a probability $P<0.05$. The analyses were carried out using the PAST 3.14 software (Hammer et al., 2001; ohammer@nhm.uio.no) and SPSS Statistics v.22 software (IBM Corp, Armonk, NY).

\section{Results}

Chemistry of the sediment and the sediment interstitial water

In the superficial sediment, the average $\mathrm{C}: \mathrm{N}$ molar ratio was significantly higher in the limnocorrals with charophytes (Tables S2, S5). In the sub-superficial sediment, the presence of charophytes was accompanied by significantly higher $\% \mathrm{C}$ and $\% \mathrm{~N}$ (Tables S2, S5). No significant effect was found due to the radiation factor. Furthermore, no significant changes in the chemistry of the sediment interstitial water were detected regarding either of the two factors.

Bacterial (and archaeal) communities under different experimental conditions

Comparing the two sediment layers (regardless of experimental treatments), the average bacterial density was significantly different $(F=20.3, P<0.001)$; the periphytic bacteria density almost doubled that from the sub-superficial sediment (Fig. 1). As for the effect of radiation, when the UVR was removed, the bacterial density was significantly higher (Fig. 1a; Table 1), but it is remarkable that the highest density was reached in the limnocorrals without UVR and with charophyte meadow (Fig. 1a). In the sub-superficial sediment, the tested factors did not significantly affect the bacterial density, although it was under the condition with the presence of charophytes and filtered UVR where the highest density was, again, observed (Fig. 1b).

Of the total number of analysed DNA sequences (including all the samples), no more than $6 \%$ were unclassified, $30 \%$ were bacteria but not classified, $0.4 \%$ were Archaea and the rest were bacteria classified in 16 phyla (Table 2). The total richness of bacterial phyla was higher in the superficial compared to the sub-superficial layer $(16 \pm 0$ and $11 \pm 0$ respectively; Mann-Whitney test $P<0.001)$. And it is in this superficial layer where only some differences between treatments were observed: unvegetated limnocorrals had one phylum more than those with meadows (Tables 1, S6). Only 9 of them accounted for more than $1 \%$ of each superficial and sub-superficial sample, and the five most abundant phyla (in order of 


\section{a}
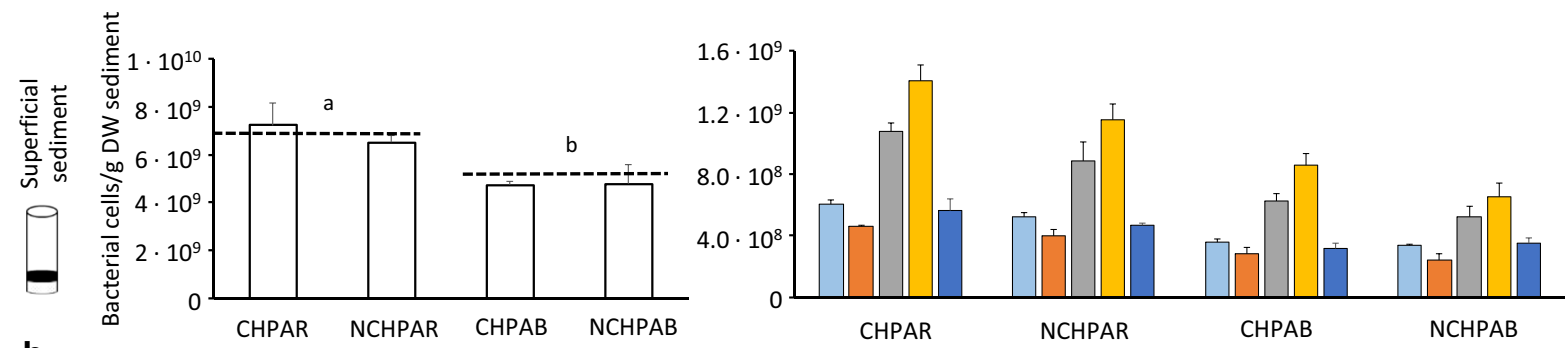

b
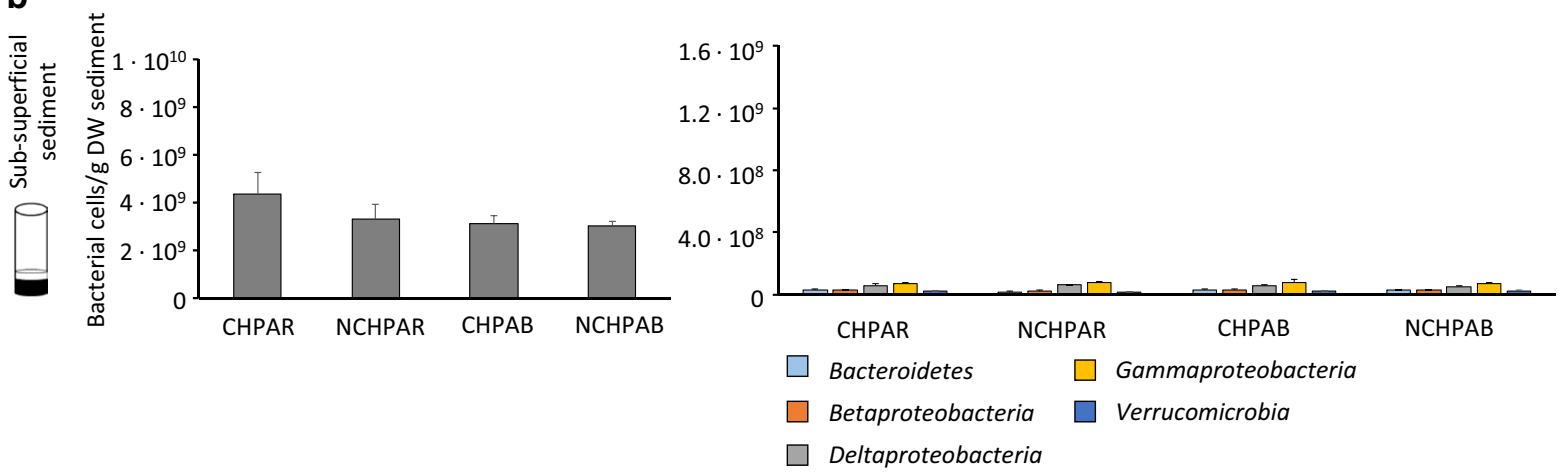

Fig. 1 a Average bacterial density in the superficial layer of the sediment (left panel) and the same variable separated by the main bacterial phyla. Lowercase letters are in accordance with the result of a post hoc Tukey analysis of density variance; the dashed line indicates the average value in PAR and PAB treatments. b The same representations of bacteria den-

abundance) were: Gamma- and Deltaproteobacteria, Bacteroidetes, Verrucomicrobia and Betaproteobacteria (Table 2; Fig. 1).

In the periphytic communities (i.e. superficial ones), Gamma- and Deltaproteobacteria, Bacteroidetes, Betaproteobacteria and Verrucomicrobia were the phyla that contributed most to the difference between the four experimental conditions (SIMPER analysis showed a contribution of 38, $37,10,9$ and 5\%, respectively). These phyla were more abundant when UVR was filtered (Table 1). In fact, they were negatively correlated with radiationrelated variables (Table S7). Among phyla, only the Gammaproteobacteria density was statistically higher when charophytes were present (Table 1). In fact, a principal component analysis based on SIMPER selected phyla separated two sets of samples, with or without UVR (Fig. 2a), the latter together with the five phyla. In addition, axis 2 separated the samples into ones with Deltaproteobacteria dominance or Gammaproteobacteria dominance. sity (total and separated by main phyla) in the sub-superficial layer of the sediment. Bars are standard errors. $\mathrm{CH}$ charophyte meadows, $\mathrm{NCH}$ without charophytes meadows, $P A B$ limnocorrals subjected to sunlight, $P A R$ limnocorrals subjected reduced UVR

In sub-superficial samples, SIMPER highlighted Gamma- and Deltaproteobacteria plus Bacteroidetes (41, 23 and 12\%, respectively). In the principal components analysis of the sub-superficial layer (Fig. 2b) most of the samples with charophytes were located in the most positive part of axis 1 , together with the three bacterial phyla. In addition, again, it was the dominance of Delta- or Gammaproteobacteria which established the division in axis 2. The correlation analysis of these phyla with environmental variables (Table S7) showed a positive correlation of Gammaproteobacteria with N-related variables and positive correlations of Deltaproteobacteria and Bacteroidetes with the carbon percentage in the sediment.

Microalgae and cyanobacteria communities under different experimental conditions

There was a strong negative correlation between the biomass of microalgae and cyanobacteria and the UVR-related variables (Table S7). When UVR was 


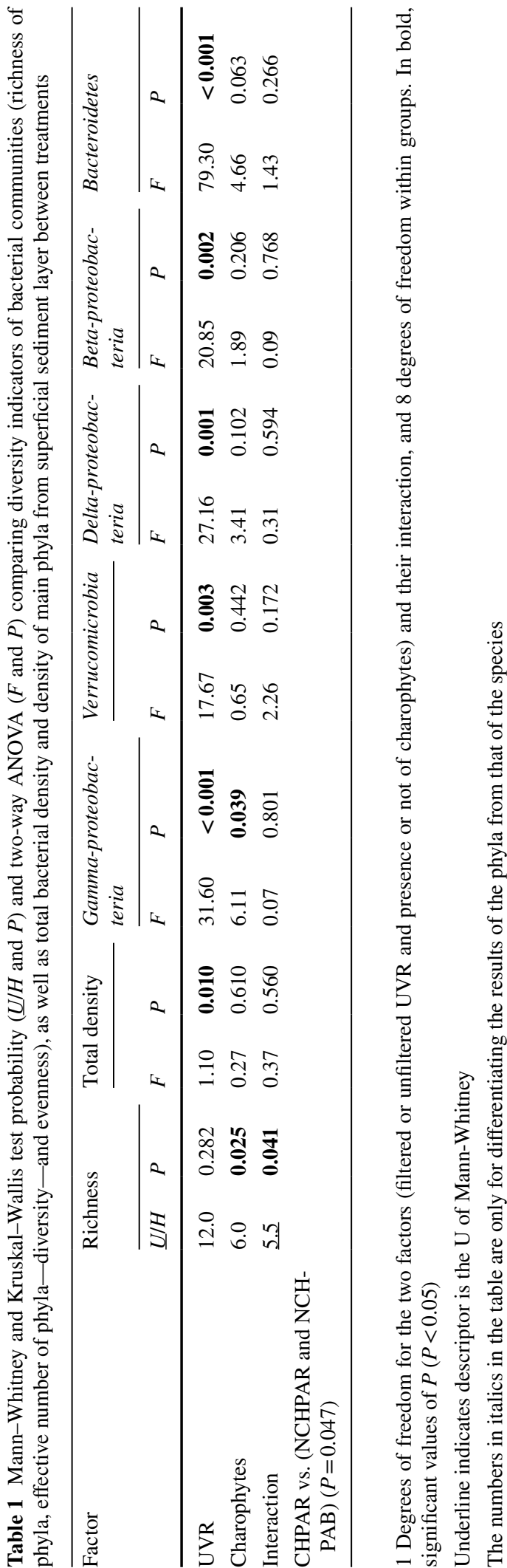

removed their biomass doubled that of those limnocorrals with full UVR, and reached its highest level if, in addition, there were charophytes (Fig. 3a; Table 3).

Among diversity indicators, only greater species richness was observed under the filtered UVR treatment compared with that of unfiltered UVR $(23 \pm 1$ vs. $20 \pm 1$, respectively; Table 3 ). All the taxonomic groups showed a negative correlation with UVR (UVA and UVB). Moreover, diatoms showed a positive correlation with the interstitial water $\mathrm{C}: \mathrm{P}$ and $\mathrm{N}: \mathrm{P}$ (Table S7). The biomass of these groups was affected by the tested factors but in different ways (Fig. 3b, c; Table 3): diatoms, the dominant group, were more abundant under the filtered UVR conditions, while Chlorophytes together with Cyanobacteria (the scarcest group) were more abundant if, in addition, charophytes were present (Table 3 ).

A multivariate analysis of ordination and classification based on populations highlighted that a specific composition was also sensitive to the tested factors, since it clustered the limnocorrals of meadows and filtered UVR separately from the others (Fig. 3d). Limnocorrals with UVR and meadows were clustered with those of filtered UVR without meadows. For their part, unvegetated limnocorrals with full UVR showed the highest variability in their composition. The filamentous chlorophyte Oedogonium sp. explained almost $60 \%$ of the dissimilarity between vegetated, without UVR, limnocorrals and those under the other conditions. When UVR was filtered, the difference between vegetated and unvegetated limnocorrals was mainly due to two filamentous chlorophytes, Oedogonium sp. and Spirogyra sp., each being present only in one of these conditions. In addition, amongst the limnocorrals with charophytes the main difference was due to UVR: the absence of chlorophytes and the disappearance of diatoms, such as Nitzschia sigmoidea (Nitzsch) W. Smith and N. tryblionella Hantzsch.

\section{Discussion}

The negative effect of UVR on freshwater aquatic microorganisms has been known for a long time (Rojo et al., 2012; Carrillo et al., 2017). However, when primary producers and bacteria are part of the community under UVR conditions the results can 
Table 2 Mean and standard error of hit percentages of the most represented $(>1 \%)$ phyla and the most representative species

\begin{tabular}{|c|c|c|c|}
\hline & Mean & Standard error & \\
\hline Bacterial phyla & 64.3 & 1.4 & \\
\hline Its main species & & & \\
\hline Actinobacteria & 1.8 & 0.1 & \\
\hline Bifidobacterium bombi & & 0.6 & 0.0 \\
\hline Bacteroidetes & 7.9 & 0.2 & \\
\hline Pedobacter kwangyangensis & & 1.3 & 0.0 \\
\hline Chlorobi & 2.5 & 0.1 & \\
\hline Ignavibacterium sp. & & 2.2 & 0.1 \\
\hline Chloroflexi & 3.5 & 0.1 & \\
\hline Longilinea arvoryzae & & 1.1 & 0.0 \\
\hline Firmicutes & 4.1 & 0.2 & \\
\hline Clostridium sp. & & 0.7 & 0.0 \\
\hline Betaproteobacteria & 5.9 & 0.3 & \\
\hline Thiobacillus sp. & & 2.7 & 0.1 \\
\hline Deltaproteobacteria & 13.3 & 0.5 & \\
\hline Desulfococcus sp. & & 2.8 & 0.1 \\
\hline Gammaproteobacteria & 17.4 & 0.8 & \\
\hline Steroidobacter denitrificans & & 4.1 & 0.5 \\
\hline Marichromatium gracile & & 2.1 & 0.1 \\
\hline Verrucomicrobia & 7.4 & 0.4 & \\
\hline Luteolibacter sp. & & 3.0 & 0.5 \\
\hline Candidatus methylacidiphilum & & 1.4 & 0.0 \\
\hline Archaea & 0.4 & 0.0 & \\
\hline Unclassified & 5.8 & 0.1 & \\
\hline Other bacteria & 29.9 & 1.3 & \\
\hline
\end{tabular}

The numbers in italics in the table are only for differentiating the results of the phyla from that of the species

Data included samples from the superficial and sub-superficial sediment layers

follow different patterns. The predictable reduction in bacterial growth due to this radiation can be offset by a greater availability of organic carbon excreted by microalgae. In this vein it is known that the commensalistic phytoplankton-bacteria relationship is dependent on UVR in oligotrophic systems (Carrillo et al., 2015). However, this is not the case in the shallow lagoon considered here, which is a highly nutrient enriched environment so that no compensation effect is observed. In the periphyton biofilm (superficial layer), the abundance of both groups of organisms (bacteria and microalgae plus cyanobacteria) was greater when UVR was mostly removed. Here, we demonstrate that UVR, although not very intense in these latitudes and altitude, can negatively affect the abundance of periphytic microorganisms. This affirmation is relevant because it has been demonstrated in the periphyton from the bottom of an aquatic system, a habitat which is generally less studied than the planktonic, and even much less studied with regard to UVR as it is generally assumed that UVR does not reach the bottom. Our results warn that the foreseeable penetration of UVR to the bottom, due to loss of water level, will degrade the periphytic community: the loss of biomass and changes in composition (structure-function).

Moreover, we suggest that charophyte meadows can fuel the sediment microbial community through different mechanisms (e.g. shading and fertilizing the sediment). The surface area for attached biofilms provided by charophytes (both in the rhizoids and in the basal part of the shoots) and the reduction in the harmful effects of UVR generate a propitious microenvironment for the development of an abundant and particular microbiota. In fact, the most favourable condition for both components of the periphyton biofilm, with regard to its abundance, was the combined presence of charophyte meadows and filtered UVR. The periphyton biofilm composition with natural light and a charophyte meadow was similar to that of the biofilm without a meadow, but with filtered UVR, which demonstrates a beneficial charophyte shading effect on the biofilm. This fact would agree with the recent results of Dai et al. (2019) who observed a greater abundance of some bacterial groups in environments with macrophytes (angiosperms), and with Xiao et al. (2020) who stated that the reduction of radiation doses, mainly by the shading effect exerted by submerged macrophytes, favoured nitrogen-related bacteria in the rhizosphere. The shading effect has usually been described as a negative impact for primary producers, for example, phytoplankton and epiphyton on submerged macrophytes (Sandjensen \& Sondergaard, 1981) or floating plants on phytoplankton and submerged macrophytes (Scheffer et al., 2003); however, in light of our results, it should also be seen as a protector against the increase in UVR at the bottom of wetlands.

Another macrophyte effect in the sub-superficial sediment layer was tested here. We found relationships between the main bacteria phyla with the elemental composition of the sediment, which in turn, 
Fig. 2 Two-dimensional principal components biplot describing: a the superficial sediment microbial community of the limnocorrals based on their main bacterial phyla density, and b the sub-superficial sediment microbial community of the limnocorrals based on the number of hits of the main phyla. The order of the main phyla is also indicated. Abbreviations as in Fig. 1

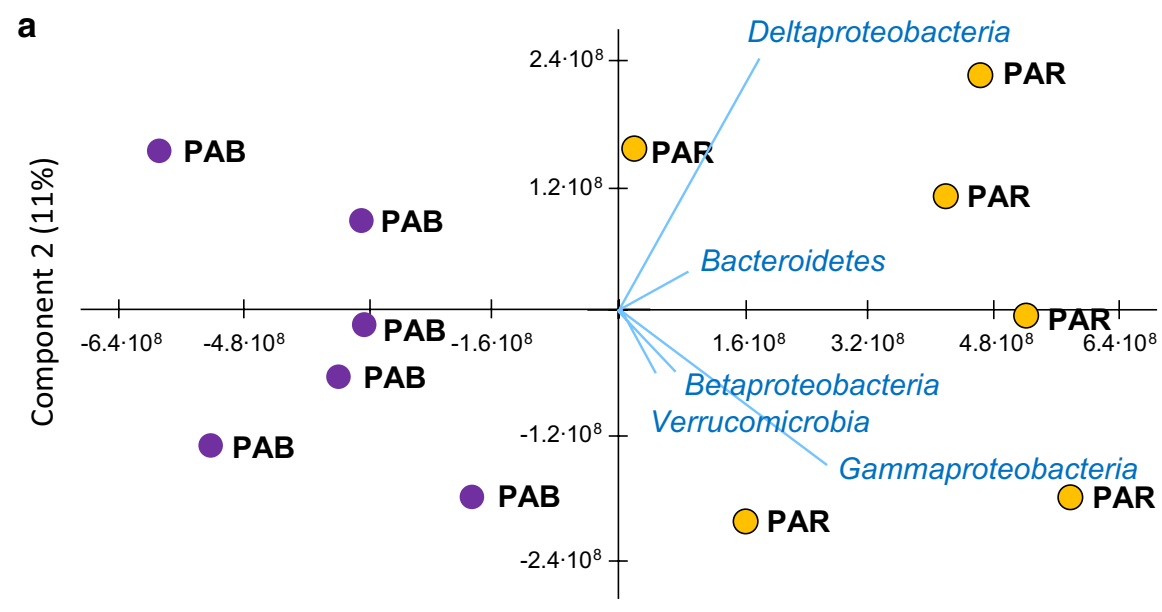

Component 1 (87\%)

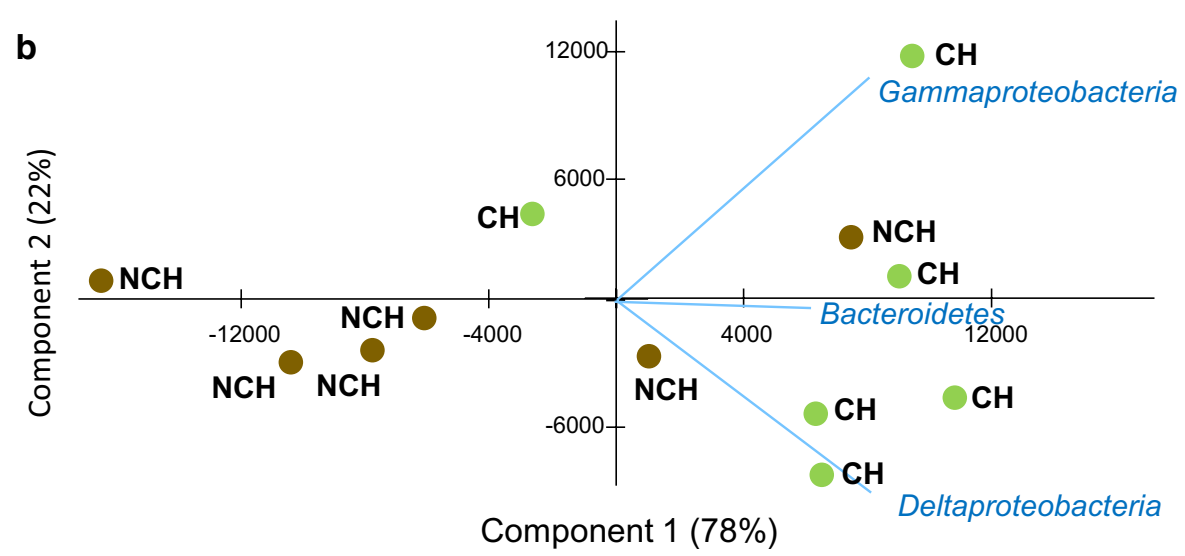

were favoured by the biological activity of macrophytes (increased $\% \mathrm{C}$ and $\% \mathrm{~N}$ ). The increase in the proportion of these elements is related to the contribution of organic matter rich in carbon and nitrogen through charophyte senescence and the exudation of organic compounds (Rodrigo et al., 2013; Rojo et al., 2020). Thus, our results with regard to the bacterial community in the sediment suggest that UVR is the driving force affecting this community in the superficial layer, while submerged macrophytes seem to influence mainly the community deeper in the sediment. Summarising, charophytes indirectly benefit the sediment microbial community by mitigating the increase in UVR and providing elemental nutrients to the sediment. This opens up an interesting research line that currently deserves more attention (Xian et al., 2020).

We found that 12 phyla made up over $63 \%$ of read sequences, and only 9 phyla accounted for more than $1 \%$ of sequences in each sample; similar proportions were observed in a macrophytes-sediment experiment in a Shanghai river (Dai et al., 2019). Thus, in the bottom sediments of wetlands there is a largely unknown bacterial biosphere, as has been highlighted in other freshwater systems (Fang et al., 2015). Some phyla and genus were co-dominant, so that only a few sets of metabolic functions were repeated (Table S8). A similar lack of combinations was described in 
a

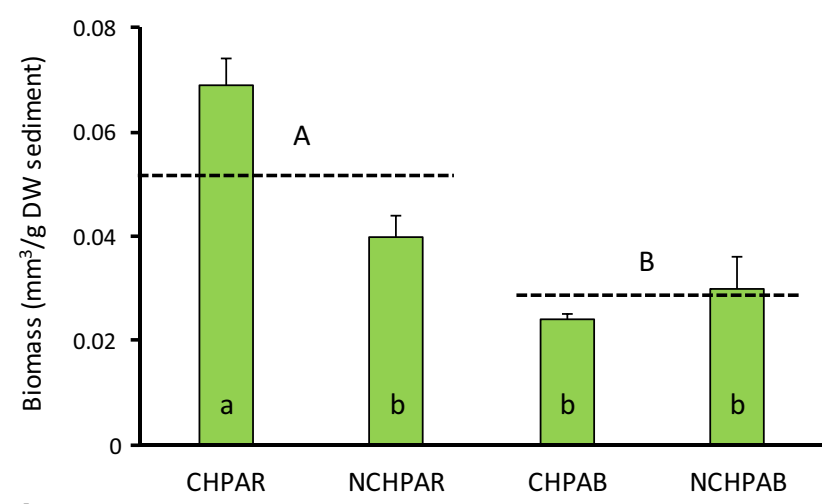

b

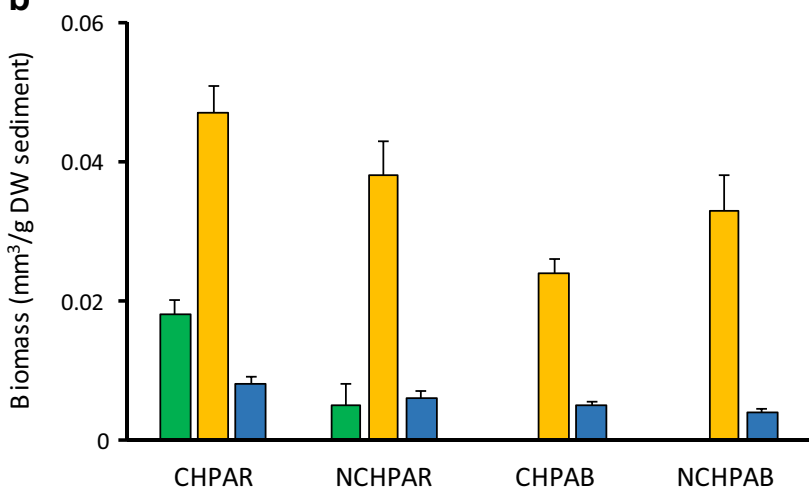

C

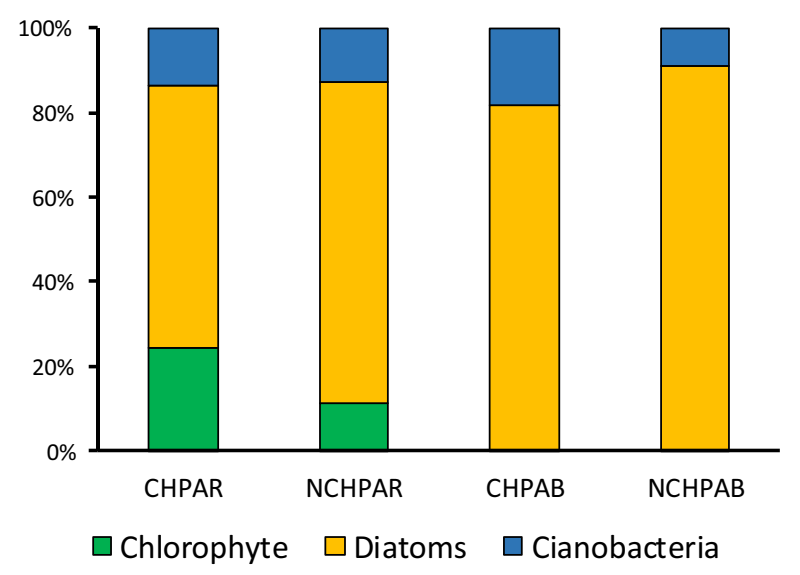

d

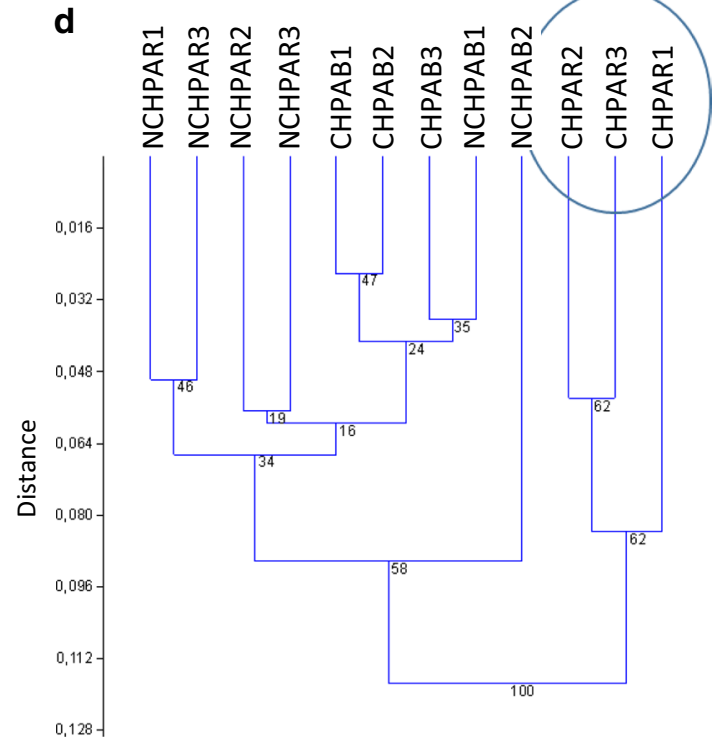

Fig. 3 Structural differences in periphytic microalgae and cyanobacteria communities (MC) inhabiting the sediment superficial layer under the four experimental conditions (presence or not of charophytes, and filtered or unfiltered UVR; abbreviations as in Fig. 1). a Average and standard error (thin bars) of the biomass; the capital letters indicate statistically significant differences due to the radiation treatment; the lowercase letters are in accordance with the result of a post hoc
Tukey analysis of variance on the biomass. b Average and standard error (thin bars) of the biomass of main MC groups in each experimental condition. c Percentage of total biomass for the main taxonomic groups. d Dendrogram based on the biomass of MC species of the 12 limnocorrals; the cluster-tree is based on the unweighted pair-group method with arithmetic mean (UPGMA) calculated on Euclidean distance similarity; the numbers in the nodes are the 1,000 bootstrap results 
Table 3 Two-way ANOVA parameters ( $F$ and probability $P$ ) applied on species diversity indicators and total biomass of microalgae and cyanobacteria and the main taxonomic groups

\begin{tabular}{|c|c|c|c|c|c|c|c|c|c|c|}
\hline \multirow[t]{2}{*}{ Factor } & \multicolumn{2}{|c|}{ Richness } & \multicolumn{2}{|c|}{ Total biomass } & \multicolumn{2}{|c|}{ Chlorophytes } & \multicolumn{2}{|c|}{ Diatoms } & \multicolumn{2}{|c|}{ Cyanobacteria } \\
\hline & $F$ & $P$ & $F$ & $P$ & $F$ & $P$ & $F$ & $P$ & $F$ & $P$ \\
\hline UVR & 6.3 & 0.036 & 37.8 & $<0.001$ & 43.2 & $<0.001$ & 9.7 & 0.010 & 21.7 & 0.001 \\
\hline Charophytes & 0.4 & 0.549 & 4.2 & 0.075 & 13.1 & 0.007 & 0.0 & 0.951 & 11.1 & 0.010 \\
\hline Interaction & 0.8 & 0.407 & 11.4 & 0.009 & 13.1 & 0.007 & 3.9 & 0.084 & 0.4 & 0.523 \\
\hline
\end{tabular}

1 Degree of freedom for the two factors (presence or not of charophytes and filtered or unfiltered UVR) and their interaction, and 8 degrees of freedom within groups. In bold, significant values of $P(P<0.05)$; only the response variables with significant differences are shown

wetlands with very different conditions (i.e. salinity and vegetation; Menéndez-Serra et al., 2019). When periphytic bacteria were more developed (under filtered UVR), a different combination of bacteria containing sulphur (or nitrogen) reducers with methane oxidizers was observed (Deltaproteobacteria along with Bacteroidetes and Gammaproteobacteria together with, for example, Verrucomicrobia). It has been described how the presence of macrophytes affects many microbial processes in the sediment by changing the nutrient concentrations by uptake and release during growth, by influencing oxygen levels $-\mathrm{O}_{2}$ released from roots, and $\mathrm{pH}$ and organic carbon availability (Veraart et al., 2011). The presence of rhizoids, which can penetrate deep in the sediment (Vermeer et al. 2003), can create heterogeneous oxygen conditions affecting both aerobic and anaerobic reactions (e.g. nitrification and denitrification processes) generating micro-environments which favour certain bacterial communities. For instance, the oxygen released into the sediment can hamper methanogenic microorganisms and enhance methane oxidizers (Fritz et al., 2011; Ribaudo et al., 2011). Our results clearly indicate that the effect of meadows can reach the sub-superficial sediment bacterial communities, with phyla associated with carbon and nitrogen cycles being the most influenced. A greater presence of Delta- and Gammaproteobacteria (Table S8) is established and, as was observed in the superficial sediment layers, their distribution seems exclusive, i.e. either one or the other.

With respect to periphytic primary producers, there were two groups that make up the greatest proportion of biomass: diatoms and chlorophytes. These groups presented a different pattern: diatoms turned out to be UVR resistant, while chlorophytes (i.e. the filamentous Oedogonium and Spirogyra genera) only appeared when UVR was filtered. Diatom resistance to UVR is considered an evolutionary trait related to the screen-protection provided by the frustule against UVR (Aguirre et al., 2018). However, although diatoms were present in all conditions, their composition changed. When UVR was present, two large species of the genus Nitzschia did not appear and the biomass was lower. These large pennate diatoms play an important role in the generation of biofilms, which provide a suitable microenvironment for bacterial communities (Landoulsi et al., 2011; Hou et al., 2020) so that their loss is relevant to the entire microbial community.

In conclusion, we have tested that the sediment microbial community is altered even by small doses of UVR on the Mediterranean coast by decreasing the periphyton abundance (both bacteria and microalgae involved in $\mathrm{C}$ and $\mathrm{N}$ metabolism) and changing their metabolic and trophic functions. In this context, the role of submerged macrophyte meadows becomes crucial. On the one hand, their presence minimizes the incidence of UVR on the sediment, so that the biota behaves as in locations with filtered UVR. We therefore recognize a beneficial shadow effect under the foreseeable decrease of water column depth in wetlands due to global change, which will allow the resistance of periphyton to changes in radiation quality. On the other hand, the presence of these meadows is related to greater proportions of $\mathrm{C}$ and $\mathrm{N}$ in the subsuperficial sediment layer. This higher availability of elemental nutrients covaries with the main bacterial phyla involved in their cycles. Therefore, the conservation of charophyte meadows in aquatic ecosystems is of great importance. This is even more crucial in 
the Mediterranean area, where these ecosystems are highly vulnerable to global change.

Acknowledgements We are thankful to Esther Sánchez (Master's student at the Universitat de València) and Carlos Rochera (research support technician at the Universitat de València), who effectively helped with the cytometry analysis. Special thanks to Professor María Jesús Pujalte (Universitat de València) for enlightening us with her knowledge of microbial taxonomy and function. We are grateful to José Luís Ayala (National Museum of Natural Sciences, CSIC, Madrid) who performed the sediment stoichiometric analyses and the chemical analyses of the water. Daniel Sheerin, a native English teacher and editor, improved the language in the manuscript.

Author contributions All authors listed on the title page have contributed significantly to the work. CR, EP and MAR conceived and designed the study; EP and MAR performed the field work; MS identified and counted the samples of microalgae and cyanobacteria; EP analysed the bacteria samples; CR and EP analysed and interpreted the data; EP and CR wrote the manuscript that was finally reviewed by EP, CR and MAR.

Funding Open Access funding provided thanks to the CRUE-CSIC agreement with Springer Nature. This study has been undertaken within the CGL2014-5402 Project, funded by the Spanish Ministry of Economy and Competitiveness.

Data availability Not applicable.

Code availability Not applicable.

\section{Declaration}

Conflict of interest The authors have no conflict of interest to declare.

\section{Consent for publication Not applicable.}

Ethical approval Not applicable.

Informed consent Not applicable.

Open Access This article is licensed under a Creative Commons Attribution 4.0 International License, which permits use, sharing, adaptation, distribution and reproduction in any medium or format, as long as you give appropriate credit to the original author(s) and the source, provide a link to the Creative Commons licence, and indicate if changes were made. The images or other third party material in this article are included in the article's Creative Commons licence, unless indicated otherwise in a credit line to the material. If material is not included in the article's Creative Commons licence and your intended use is not permitted by statutory regulation or exceeds the permitted use, you will need to obtain permission directly from the copyright holder. To view a copy of this licence, visit http://creativecommons.org/licenses/by/4.0/.

\section{References}

Aguirre, L. E., L. Ouyan, A. Elfwing, M. Hedblom, A. Wulff \& O. Inganäs, 2018. Diatom frustules protect DNA from ultraviolet light. Scientific Reports 8: 5138.

APHA, 2005. Standard Methods for the Examination of Water and Wastewater. American Public Health Association, Washington, DC.

Azim, M. E., M. C. Verdegem, A. A. van Dam \& M. C. Beveridge, 2005. Periphyton: Ecology, Exploitation and Management. CABI Publishing, Cambridge.

Azua-Bustos, A., A. G. Fairén, C. González-Silva, C. Ascaso, D. Carrizo, M. Fernández-Martínez, M. FernándezSampedro, L. García-Descalzo, M. García-Villadangos, M. P. Martin-Redondo, L. Sánchez-García, J. Wierzchos \& V. Parro, 2018. Unprecedented rains decimate surface microbial communities in the hyperacid core of the Atacama Desert. Scientific Reports 8: 16706.

Baron, J. S., E. K. Hall, B. T. Nolan, J. C. Finlay, J. A. Bernhardt, J. A. Harrison, F. Chan \& E. W. Boyer, 2013. The interactive effects of excess reactive nitrogen and climate change on aquatic ecosystems and water resources of the United States. Biogeochemistry 114: 71-92.

Barrado-Moreno, M. M., J. Beltrán-Heredia \& J. Martín-Gallardo, 2017. Degradation of microalgae from freshwater by UV radiation. Journal of Industrial Engineering Chemistry 48: $1-4$.

Baveye, P. C., W. Otten \& A. Kravchenko, 2019. Elucidating microbial processes in soils and sediments: microscale measurements and modelling. Frontiers in Environmental Science 7: 78.

Cabrerizo, M. J., E. W. Helbling, V. E. Villafañe, J. M. Medina-Sánchez \& P. Carrillo, 2020. Multiple interacting environmental drivers reduce the impact of solar UVR on primary productivity in Mediterranean lakes. Scientific Reports 10: 19812.

Canfield, D. E., A. N. Glazer \& P. G. Falkowski, 2010. The evolution and future of earth's nitrogen cycle. Science 330: 192-196.

Carrillo, P., J. M. Medina-Sánchez, C. Durán, G. Herrera, V. E. Villafañe \& E. W. Helbling, 2015. Synergistic effects of UVR and simulated stratification on commensalistic phytoplankton-bacteria relationship in two optically contrasting oligotrophic Mediterranean lakes. Biogeosciences 12: 697-712.

Carrillo, P., J. M. Medina-Sánchez, M. Villar-Argaiz, F. J. Bullejo, C. Durán, M. Bastidas-Navarro, M. S. Souza, E. G. Balseiro \& B. E. Modenutti, 2017. Vulnerability of mixotrophic algae to nutrient pulses and UVR in an oligotrophic Southern and Northern Hemisphere lake. Scientific Reports 7: 6333.

Chen, S., T. Huang, Y. Zhou, Y. Han, M. Xu \& J. Gu, 2017. AfterQC: automatic filtering, trimming, error removing and quality control for fastq data. BMC Bioinformatics 18: 80.

Dai, Y., J. Wu, F. Zhong, N. Cui, L. Kong, W. Liang \& S. Cheng, 2019. Macrophyte identity shapes water column and sediment bacterial community. Hydrobiologia 835 : $71-82$. 
Duhamel, S. \& S. Jacquet, 2006. Flow cytometric analysis of bacteria- and virus-like particles in lake sediments. Journal of Microbiological Methods 64: 316-332.

Fang, L., L. Chen, Y. Liu, W. Tao, Z. Zhang, H. Liu \& Y. Tang, 2015. Planktonic and sedimentary bacterial diversity of Lake Sayram in summer. MicrobiologyOpen 4: 814-825.

Fox, G. E., J. D. Wisotzkey \& P. Jurtshuk Jr., 1992. How close is close: $16 \mathrm{~S}$ rRNA sequence identity may not be sufficient to guarantee species identity. International Journal of Systematic Bacteriology 42: 166-170.

Fritz, C., V. A. Pancotto, J. T. M. Elzenga, E. J. W. Visser, A. P. Grootjans, A. Pol, R. Iturraspe, J. G. M. Roelofs \& A. J. P. Smolders, 2011. Zero methane emission bogs: extreme rhizosphere oxygenation by cushion plants in Patagonia. New Phytologist 190: 398-408.

Giorgi, F. \& P. Lionello, 2008. Climate change projections for the Mediterranean region. Global and Planetary Change 63: 90-104.

Gugliandolo, C., L. Michaud, A. Lo Giudice, V. Lentini, C. Rochera, A. Camacho \& T. L Maugeri, 2016. Prokaryotic community in lacustrine sediments of Byers Peninsula (Livingston Island, Maritime Antarctica). Microbial Ecology 71: 387-400.

Hammer, Ø., D. A. T. Harper \& P. D. Ryan, 2001. PAST: paleontological statistics software package for education and data analysis. Palaeontologia Electronica 4: 9 pp. Available on internet at https://www.nhm.uio.no/english/resea rch/infrastructure/past/. Accesed on July 19, 2021.

Hansson, L. A., C. Brönmark, P. A. Nilsson \& K. Åbjörnsson, 2005. Conflicting demands on wetland ecosystem services: nutrient retention, biodiversity or both? Freshwater Biology 50: 705-714.

Harrison, J. W. \& R. E. H. Smith, 2009. Effects of ultraviolet radiation on the productivity and composition of freshwater phytoplankton communities. Photochemical and Photobiological Sciences 8: 1218-1232.

Hillebrand, H., C. D. Dürselen, D. Kirschtel, U. Pollingher \& T. Zohary, 1999. Biovolume calculation for pelagic and benthic microalgae. Journal of Phycology 35: 403-424.

Hilt, S. \& E. M. Gross, 2008. Can allelopathically active submerged macrophytes stabilize clear-water states in shallow lakes? Basic and Applied Ecology 9: 422-432.

Hou, R., Y. Wu, J. Xu \& K. Gao, 2020. Solar UV radiation exacerbates photoinhibition of a diatom by antifouling agents Irgarol 1051 and diuron. Journal of Applied Phycology 32: 1243-1251.

IPCC, 2014. Summary for policymakers. In Field, C. B. et al. (eds), Climate Change 2014: Impacts, Adaptation, and Vulnerability. Contribution of Working Group II to the Fifth Assessment Report of the Intergovernmental Panel on Climate Change. Cambridge University Press, Cambridge: $1-32$.

Jeppesen, E., B. Kronvang, J. E. Olesen, J. Audet, M. Søndergaard, C. C. Hoffmann, H. E. Andersen, T. L. Lauridsen, L. Liboriussen, S. E. Larsen, M. Beklioglu, M. Meerhoff, A. Özen \& K. Özkan, 2011. Climate change effects on nitrogen loading from cultivated catchments in Europe: implications for nitrogen retention, ecological state of lakes and adaptation. Hydrobiologia 663: 1-21.

Jeppesen, E., M. Meerhoff, T. A. Davidson, D. Trolle, M. Søndergaard, T. L. Lauridsen, M. Beklioğlu, S. Brucet,
P. Volta, I. González-Bergonzoni \& A. Nielsen, 2014. Climate change impacts on lakes: an integrated ecological perspective based on a multi-faceted approach, with special focus on shallow lakes. Journal of Limnology 73: 84-107.

Jordan, S. J., J. Stoffer \& J. A. Nestlerode, 2011. Wetlands as sinks for reactive nitrogen at continental and global scales: a meta-analysis. Ecosystems 14: 144-155.

Jost, L., P. DeVries, T. Walla, H. Greeney, A. Chao \& C. Ricotta, 2010. Partitioning diversity for conservation analyses. Diversity and Distributions 16: 65-76.

Klindworth, A., E. Pruesse, T. Schweer, J. Peplies, C. Quast, M. Horn \& F. O. Glöckner, 2013. Evaluation of general 16S ribosomal RNA gene PCR primers for classical and next-generation sequencing-based diversity studies. Nucleic Acids Research 41: e1.

Landoulsi, J., K. E. Cooksey \& V. Dupres, 2011. Review Interactions between diatoms and stainless steel: focus on biofouling and biocorrosion. Biofouling 27: 1105-1124.

Manrique, J. M., A. Y. Calvo, S. R. Halac, V. E. Villafañe, L. E. Jones \& E. W. Helbling, 2012. Effects of UV radiation on the taxonomic composition of natural bacterioplankton communities from Bahía Engaño (Patagonia, Argentina). Journal of Photochemistry and Photobiology B: Biology 117: $171-178$.

Mayer, L. M., L. L. Schick, K. Skorko \& E. Boss, 2006. Photodissolution of particulate organic matter from sediments. Limnology and Oceanography 51: 1064-1071.

Menéndez-Serra, M., X. Triadó-Margarit, C. Castañeda, J. Herrero \& E. O. Casamayor, 2019. Microbial composition, potential functional roles and genetic novelty in gypsum-rich and hypersaline soils of Monegros and Gallocanta (Spain). Science of the Total Environment 650: 343-353.

Morina, J. C., E. M. Morrissey \& R. B. Franklin, 2018. Vegetation effects on bacteria and denitrifier abundance in the soils of two tidal freshwater wetlands in Virginia. Applied and Environmental Soil Science 2018: 4727258.

Navarro, J. B., D. P. Moser, A. Flores, C. Ross, M. R. Rosen, H. Dong, G. Zhang \& B. P. Hedlund, 2009. Bacterial succession within an ephemeral hypereutrophic Mojave Desert Playa Lake. Microbial Ecology 57: 307-320.

Neubauer, S. C., K. Givler, S. K. Valentine \& J. P. Megonigal, 2005. Seasonal patterns and plant-mediated controls of subsurface wetland biogeochemistry. Ecology 86: 3334-3344.

Orland, C., K. M. Yakimovich, N. C. S. Mykytczuk, N. Basiliko \& A. J. Tanentzap, 2020. Think global, act local: the small-scale environment mainly influences microbial community development and function in lake sediment. Limnology and Oceanography 65: S88-S100.

Parcerisas, L., J. Marrull, J. Pino, E. Tello, F. Coll \& C. Basnou, 2012. Land use changes, landscape ecology and their socioeconomic driving forces in the Spanish Mediterranean coast (El Maresme County, 1850-2005). Environ Science and Policy 23: 120-132.

Puche, E., C. Rojo \& M. A. Rodrigo, 2020. Multi-interaction network performance under global change: a shallow ecosystem experimental simulation. Hydrobiologia 847: 3549-3569. 
Rabalais, N. N. 2002. Nitrogen in aquatic ecosystems. Ambio 31: 102-112.

Ribaudo, C., M. Bartoli, E. Racchetti, D. Longhi \& P. Viaroli, 2011. Seasonal fluxes of $\mathrm{O}_{2}$, DIC and $\mathrm{CH}_{4}$ in sediments with Vallisneria spiralis: indications for radial oxygen loss. Aquatic Botany 94: 134-142.

Rodrigo, M. A., C. Rojo, M. Álvarez-Cobelas \& S. Cirujano, 2007. Chara hispida beds as a sink of nitrogen: evidence from growth, nitrogen uptake and decomposition. Aquatic Botany 87: 7-14.

Rodrigo, M. A., C. Rojo, J. L. Alonso-Guillén \& P. Vera, 2013. Restoration of two small Mediterranean lagoons: the dynamics of submerged macrophytes and factors that affect the success of revegetation. Ecological Engineering 54: $1-15$.

Rojo, C., G. Herrera, M. A. Rodrigo, M. J. Ortíz-Llorente \& P. Carrillo, 2012. Mixotrophic phytoplankton is enhanced by UV radiation in a low altitude, P-limited Mediterranean lake. In Salmaso, N. et al. (eds), Phytoplankton Responses to Human Impacts at Different Scales. Developments in Hydrobiology 221. Springer, Dordrecht: 97-110.

Rojo, C., Z. Mosquera, M. Álvarez-Cobelas \& M. Segura. 2017a. Microalgal and cyanobacterial assemblages on charophytes: a metacommunity perspective. Fundamental and Applied Limnology 190: 97-115.

Rojo, C., G. Herrera, J. M. Medina-Sánchez, M. Villar-Argaiz, C. Durán \& P. Carrillo, 2017b. Are the small-sized plankton communities of oligotrophic ecosystems resilient to UVR and P pulses? Freshwater Sciences 36: 760-773.

Rojo, C., E. Puche \& M. A. Rodrigo, 2019. The antagonistic effect of UV radiation on warming or nitrate enrichment depends on ecotypes of freshwater macroalgae (charophytes). Journal of Phycology 55: 714-729.

Rojo, C., S. Sánchez-Carrillo, M. A. Rodrigo, E. Puche, S. Cirujano \& M. Álvarez-Cobelas, 2020. Charophyte stoichiometry in temperate waters. Aquatic Botany 161: 103182.

Rubio, F., C. Rojo, E. Núñez-Olivera \& M. A. Rodrigo, 2015. Effects of UVB radiation exposure from the molecular to the organism level in macrophytes from shallow Mediterranean habitats. Aquatic Botany 120: 112-120.

Rysgaard, S. B., P. B. Christensen \& L. P. Nielsen, 1995. Seasonal variation in nitrification and denitrification in estuarine sediment colonized by benthic microalgae and bioturbating fauna. Marine Ecology Progress Series 126: 111-121.

Sabater, S., H. Guasch, M. Ricart, A. Romaní, G. Vidal, C. Klünder \& M. Schmitt-Jansen, 2007. Monitoring the effect of chemicals on biological communities. The biofilm as an interface. Analytical and Bioanalytical Chemistry $387: 1425-1434$.

Sandjensen, K. \& M. Sondergaard, 1981. Phytoplankton and epiphyte development and their shading effect on submerged macrophytes in lakes of different nutrient status. Internationale Revue der Gesamten Hydrobiologie 66: $529-552$.
Scheffer, M., S. Szabo, A. Gragnani, E. H. van Nes, S. Rinaldi, N. Kautsky, J. Norberg, R. M. M. Roijackers \& R. J. M. Franken, 2003. Floating plant dominance as a stable state. Proceedings of the National Academy of Sciences of USA 100: 4040-4045.

Shannon, C. E. \& W. Weaver, 1949. The Mathematical Theory of Communication. University of Illinois Press, Urbana.

Song, G. C., H. J. Sim, S. G. Kim \& C. M. Ryu, 2016. Rootmediated signal transmission of systemic acquired resistance against above-ground and below-ground pathogens. Annals of Botany 118: 821-831.

Sparks, D. L., A. L. Page, P. A. Helmke, R. H. Loeppert, P. N. Soltanpour, M. A. Tabatabai, C. T. Johnston \& M. E. Sumner, 1996. Methods of Soil Analysis: Part 3 Chemical Methods. ASA and ASSA, Madison.

Spring, S., R. Schulze, J. Overmann \& K. H. Schleifer, 2000. Identification and characterization of ecologically significant prokaryotes in the sediment of freshwater lakes: molecular and cultivation studies. FEMS Microbiology Reviews 24: 573-590.

Veraart, A. J., W. J. J. de Bruijne, J. J. M. de Klein, E. T. H. M. Peeters \& M. Scheffer, 2011. Effects of aquatic vegetation type on denitrification. Biogeochemistry 104: 267-274.

Vermeer, C. P., M. Escher, R. Portielje \& J. J. M. de Klein, 2003. Nitrogen uptake and translocation by Chara. Aquatic Botany 76: 245-258.

Wang, Q., G. M. Garrity, J. M. Tiedje \& J. R. Cole, 2007. Naïve Bayesian classifier for rapid assignment of rRNA sequences into the new bacterial taxonomy. Applied and Environmental Microbiology 73: 5261-5267.

Wu, Y., J. Liu \& E. R. Rene, 2018. Periphytic biofilms: a promising nutrient utilization regulator in wetlands. Bioresource Technology 248: 44-48.

Xian, L., T. Wan, Y. Cao, J. Sun, T. Wu, A. Apudo Apudo, W. Li \& F. Liu, 2020. Structural variability and functional prediction in the epiphytic bacteria assemblies of Myriophyllum spicatum. Current Microbiology 77: 3582-3594.

Xiao, Y., X. Yin, L. Chen, J. Wang, Y. Wang, G. Liu, Y. Hua, X. Wan, N. Xiao, J. Zhao \& D. Zhu D, 2020. Effects of illumination on nirS denitrifying and anammox bacteria in the rhizosphere of submerged macrophytes. Science of the Total Environment 760: 143420.

Zhang, Z. S., X. L. Song, X. G. Lu \& Z. S. Xue, 2013. Ecological stoichiometry of carbon, nitrogen, and phosphorus in estuarine wetland soils: influences of vegetation coverage, plant communities, geomorphology, and seawalls. Journal of Soils and Sediments 13: 1043-1051.

Publisher's Note Springer Nature remains neutral with regard to jurisdictional claims in published maps and institutional affiliations. 